\title{
Relating Technology Based CRM to Service Quality in the Telecommunications Industry in Arusha City, Tanzania
}

\author{
Aneth Herman Foya ${ }^{1}$, James Kilika ${ }^{2}$, Stephen Muathe ${ }^{2}$ \\ ${ }^{1}$ Department of Marketing, St. Augustine University, Arusha, Tanzania \\ ${ }^{2}$ Department of Business Administration, Kenyatta University, Nairobi, Kenya
}

\section{Email address:}

aneth7@gmail.com (A. H. Foya), kilikam3@yahoo.com (J. Kilika), muathesm@yahoo.com (S. Muathe)

\section{To cite this article:}

Aneth Herman Foya, James Kilika, Stephen Muathe. Relating Technology Based CRM to Service Quality in the Telecommunications Industry in Arusha City, Tanzania. Science Journal of Business and Management. Vol. 3, No. 6, 2015, pp. 209-218.

doi: $10.11648 /$ j.sjbm.20150306.11

\begin{abstract}
Customer Relationship management concept is vital not only to service based organizations but also to manufacturing based industries. CRM enhances the ability of businesses to survive in the context of a changing business environment characterized by high competition. Theoretically, CRM has been advocated due to the role that it can play in creating, nurturing and maintaining mutual relationships between an organization and its customers. This study examined the effect of the technology based CRM on service quality in the Telecommunications industry in Arusha, Tanzania. The study used an integrated theoretical framework that conceptualized the constructs for the technology based CRM using both theories on technology and those on customer service relationship management. Four hypotheses relating the independent and dependent variables were tested. The study used a descriptive survey design that was cross sectional in nature. The population of the study consisted of diverse stakeholders within the telecommunication industry in Tanzania. Those that comprised the population included four telecommunications companies, their respective distributors and subscribers, estimated at a total of $26,514,895$. A sample of 323 respondents was drawn and data obtained from each using a predetermined questionnaire that was self administered to each respondent. The data obtained from the field was analyzed by both descriptive and inferential statistics and multiple linear regression was employed to test the hypotheses. The descriptive findings of the study indicated that mobile phone companies have employed the technology based CRM systems to a good extent (Mean=4) so as to align their business activities towards delivering services to customers. The results of the hypotheses tested indicated that there was no statistically significant relationship between system automation and service quality as well as system functionality and service quality $(\beta=-.109, p>0.05 ; \beta=-.244, p>0.05$ respectively). However, the study found that there is a statistically significant relationship between system user acceptance, service quality, system integration and service quality $(\beta=-.588 ; p<$ $0.05 ; \beta=.814, p<0.05$ respectively). The study suggested that the mobile service organizations need to invest not only in technology based CRM but also to invest in the aspect of internal marketing since it has potential to enhance the level of service quality offered by mobile phone companies. The findings of the study called on future research on technology based CRM to incorporate the aspects of individual IT users' demographic and psychological characteristics.
\end{abstract}

Keywords: Customer Relationship Management, Service Quality, Telecommunication Industry, Technology, Technology Based CRM

\section{Introduction}

The Customer Relationship Management (CRM) concept evolved around 1980's and companies started to rapidly adopt it in the late 1990's. The concept has been defined differently by different authors; some have defined the concept in terms of relationships without associating it with technology, while others have defined it in terms of relationships closely associated with technology $[2,11]$. Despite the differences in defining the concept, the core objective of CRM remains that of creating, nurturing and maintaining a mutual relationship between companies and their respective customers. The scholars who defined CRM by associating it with technology suggested that CRM is a combination of marketing strategies and technology [11], and therefore technology contributes a relatively high proportion 
of CRM since technology enhances the implementation of CRM. Curry and Kkolou, thus concluded that CRM is a concept that is technology oriented [10]. The increasing use of digital technologies such as internet is changing what is expected in terms of customers' management. CRM applications of computerized technological innovations are suitable to collecting data, analyzing it, interpreting customer behavior, and developing productive models that respond on time with customized communication to deliver solutions to customer needs [9]. The computerized technology has enabled data sharing, automation and management of information in a way that has facilitated marketers to better understand customer preferences, buying behaviors and develop marketing mix based responses that are suited to the customers' requirements.

There are several dimensions of technology applicable in CRM that have been documented in the main theories used in the area of technology that include; automation, functionality, acceptance by users and integration [47]. Automation involves the use of systems for operating equipment such as machinery or processes in companies with minimal human intervention or with no human intervention at all. Functionality implies the ability of a particular technology to cater for the needs of the users and addresses the concern as to whether the technology has a useful purpose to users and can perform well the activities intended. Acceptance by users refers to the willingness of users to believe that the technology in application is working according to their needs. Integration is the ability of the technology to combine processes and systems to give out the desired results as intended to accomplish by the company. All the four dimensions are integrated to support CRM programs so as to enable companies to create, nurture and maintain relationships between a business and its customers to ensure customer's value is maximized. When the technology dimensions are integrated into marketing activities, the resultant Technology based CRM programs highly support the basic concern of marketers for ensuring delivery of quality to the market. In most cases, the CRM programs come at the stage of customer service to enhance customer care that offers potential to strengthen relationships with existing customers. The technology based CRM programs impact an organization's customer service activities and will manifest through the dimensions of service quality $[49,50]$. Service quality has been described as an assessment of how well a delivered service conforms to the client's expectations [20, 21, 22]. Most business operators often assess the service quality provided to their customers in order to improve their service, to quickly identify problems, and to better assess client satisfaction level.

There are several features defining the service quality which are drawn from the nature of services [17, 18, 22] that include perishability, intangibility, variability and inseparability. Perishability of services reflect the fact that services cannot be stored in inventory as tangible products can, for instance a vacant hotel room is a lost service opportunity. In the case of Intangibility, unlike products, services cannot be touched, felt or tried out by buyers before purchase and there is no exchange of ownership from buyer to seller. Services vary due to the laborintensive nature in service business; because the activities of personnel ultimately determine the quality of the service. Services cannot be separated from the service provider, and services are consumed at the time they are produced, therefore, the service provider generates and renders the service to the consumer as per consumer needs [39]. Due to the implied nature of service quality derived from the nature of services, the best judge of the quality of the service remains to be the customer, who consumes the service and makes evaluations based on prior expectations [16]. However, the assessments of service quality may vary with industry, product or service. There are indications that the adopted service quality models need to be assessed along the diversity of industries and the products or services especially those newly emerging service oriented sectors [1, 42]. This study identified the telecommunication industry for investigation of the two constructs of technology based CRM and service quality.

Recent global trends point to the fact that communication is increasingly becoming a paramount and unavoidable aspect of both business and social life. Telecommunications industry facilitates this by providing data, internet, voice services, graphics, television and video at increasing speed and through diverse channels [4]. The market for this industry includes individual customers, small businesses customers and large corporate customers including governments and government bodies. The customers' profile of this industry is quite gigantic and they prefer advanced technology such as the use of wireless connections to computers just as it is with their mobile phones. However, the service providers in this industry adopt marketing mix programs for the purpose of differentiation due to stiff competition, focusing on all the 7Ps of product, price, place, promotion, people, physical evidence and process [44].

The context of this study was the telecommunications industry in Tanzania. Tanzania is the second largest telecoms market in East Africa, after Kenya. The most important telecoms companies in Tanzania include Airtel, Vodacom, Zantel and Tigo. All of these companies are in fierce competition while at the same time the entire sector remains open for new entrants from both within and outside Tanzania [33]. Comparing Tanzania with other countries in the East African region, the Tanzanian sector may be the least studied [28]. The findings of the study done Materu and Diyamett [28] indicated that the general public lacks awareness on the developments in the telecoms sector, there is low customer service, poor quality due to substandard handsets and a weakness of time based internet access charge models. Therefore, it was the view of the researchers that an empirical study is required to demonstrate the links between technology based CRM and service quality in telecommunications industry in Tanzania. 


\section{Research Problem}

The findings of previous research [28] indicated that there is a need to enhance the CRM programs in telecoms industry in Tanzania so as to improve the service quality levels. The required research needs to apply service quality models to relate the various dimensions of service quality with the technology based CRM. In spite of this call for research on aspects of service quality in the technology dependent mobile sector in Tanzania, researches done in other parts of the world seem to be insufficient in offering guidelines on how to conceptualize CRM and service quality in the country. Researches so far done, have not integrated the concepts of Technology based CRM and Service Quality Management in a single empirical investigation in order to explain their behavior and relationship. The researches have however raised the need for the integration of concepts connected with quality management in technology based CRM research. The previous researches have focused on three streams namely; assessing the role of CRM in relationship management [7, 27, $38,45]$, integration of CRM with quality management [10, 29, 43, 49,] and identification of areas of complementarity between CRM and technology [40].

Those researches focusing on the role of CRM in relationship management have found that CRM is vital in building the relationship between customers and the company, which in turn determines the profitability of the company [7, $27,38,45]$. Those focusing on the integration of CRM with quality management have found that CRM alone cannot bring customer value but it has to be integrated well with the related marketing functions and quality in order to give out the maximum of the desired results [10, 27, 29, 43, 49]. The last stream focusing on the complementarity between CRM and technology has found that technology is an enabler of CRM, since it improves customer relationship by centralizing information and data and provides timely and accurate information to customers [40]. In addition, several studies done on CRM and aspects of Technology aimed at evaluating the contribution of Technology to effective CRM have shown that implementation of CRM largely depends on the state of Technology and that the Technology and CRM are statistically related $[4,10,37,41]$.

In theory and practice, organizations design their Technology based CRM programs in order to enhance their customer relationship management activities whose effectiveness is manifested through the dimensions of service quality [3, 35, 36]. In spite of this, it is clear that these previous researches have only considered CRM and Technology without relating it to the area of service quality $[4,41]$. The purpose of this study was therefore to respond to the stated research gaps with the main objective of assessing the effect of technology based CRM system on service quality. The study identified four objectives, the first objective sought to assess the effect of CRM system automation on service quality in the Telecommunication Industry in Arusha City, the second objective sought to examine the effect of CRM system functionality on service quality in the Telecommunication Industry in Arusha City, the third objective sought to establish the effect of CRM system user acceptance on service quality in the Telecommunication Industry in Arusha City and the last objective sought to establish the effect of CRM system integration on service quality in the Telecommunication Industry in Arusha City.

\section{Significance of the Study}

The findings of the study are relevant in several ways. First, the findings of the study contribute to an understanding in the area of marketing on how to integrate the various theoretical models of technology based CRM and service quality. Secondly the findings show how customer satisfaction can be enhanced, which in turn helps to achieve customer retention. The findings provide Management of Telecommunications companies with an understanding on how technology based CRM relates to service quality which is a key success factor for companies in a competitive environment. Also, the findings of this study have presented some information to cover some of the research gaps from the previous studies and enable scholars to gain more understanding on the concerned topic. Lastly, this study is expected to add on to the number of studies done in telecommunications industry in Tanzania.

\section{Literature Review}

\subsection{Theoretical Review}

The study reviewed several theories on technology based CRM and service quality. The Information Technology (IT) based model was used as the main theory to guide the conceptualization and hypotheses development in conjunction with Technology Acceptance Model (TAM) and Unified Theory of Acceptance and Use of Technology (UTAUT), CRM pyramid model, IDIC and SERVQUAL model [3]. The information technology based model highlights the importance of information technology (IT)based service options among service providers who are using IT to reduce costs and create value-added services for their customers. The model attempts to explain the relationship between IT-based services and customers' perceptions of service quality. The model focuses on the linkages among the service dimensions as measured by SERVQUAL model [51]. The model creates a link with service quality dimensions as measured by SERVQUAL model [35]. On the other hand CRM pyramid model and IDIC model suggested that CRM activities are highly supported by the presence of technology, thus providing evidence that CRM is a combination of technology and strategies $[8,25]$. Thus the concept of CRM has been popular not only in the business arena but also among different scholars.

[31] CRM is the methodology based on new information technology that helps companies to attain their long held goals for improving customer satisfaction. CRM is also comprised of 
the organization, processes and systems through which an organization manages its relationships with its customers. Some studies have considered CRM as the core business strategy that integrates internal processes and functions, and external networks, to create and deliver value to targeted customers at a profit [8]. It is grounded on high quality customer - related data and enabled by information technology [8]. This definition is similar to that of several other scholars $[17,21]$ who defined CRM as the overall data management activities and process of building and maintaining profitable customer relationships by delivering superior customer value and satisfaction. Thus CRM is customer centric as it focuses on delivering superior customer value and satisfaction by providing high quality goods and services to customers. Service quality on the other hand is the ability of the organization to meet or exceed customers' expectations [5]. An understanding of customers is central to understanding service quality, although there has not been less agreement about how to operationalize service quality as a construct. Therefore, it becomes difficult to define and measure service quality [14] and hence, results to difficulty for the marketing manager to determine how much to spend on improving service quality [15]. Service quality can be measured using various approaches; however, the most common measures of service quality remains to be those used in the SERVQUAL model which has five constructs, and the same measures have been used by the study [36].

A number of studies have used various aspects of CRM. The study reviewed previous researches done on CRM and found that, first, researches focusing on assessing the role of CRM in relationship management indicate that CRM investment is vital to any organization that operates in an environment experiencing ever growing competition because of the need for survival and that most of the organizations are at their early stage of CRM implementation. CRM implementation involves change in organizational culture and other internal operations which implies that there is need for change of focus from product/service to customers. CRM focuses on customers, and attention should be paid to their needs and wants and customize the needs and wants so as to provide what exactly is needed by customers. By so doing a company will be in a better position of satisfying customers. However, CRM is integrated with other functions within the organization in order to give the greatest value to customers by satisfying them [7, 38, 45]. Secondly, the findings on previous researches focusing on integration of CRM and quality management showed that the implementation of CRM requires a shared vision and mission within the organization, and this goes in line with the focus on developing and managing the internal marketing that can add more value to customers by promoting the quality of products and services. Therefore, when CRM is integrated with quality, then customers' value is created through customers' satisfaction [10, 29, 43, 49]. Also, the studies focusing on CRM and technology complementarity showed that CRM technology is a vital tool in collecting, analyzing and storing data and information from customers. The information analyzed and stored is useful in tailoring the products and services needed by customers. Also this tool was used in creating and maintaining the relationship between customers and organizations [40].

\subsection{Conceptualization and Hypotheses}

In view of the theoretical and empirical literature reviewed to answer the main research question under investigation, the study proposed a suitable conceptual framework presented in figure 1. The dependent variable of the study was Service Quality. Service Quality was operationalized through service reliability, service responsiveness, assurance, empathy and service tangibility. The study proposed that service quality was to be determined by the state of technology based CRM in the mobile phone companies. The independent variable of the study was technology based CRM which was operationalized through system automation, system functionality, system user acceptance and system integration.

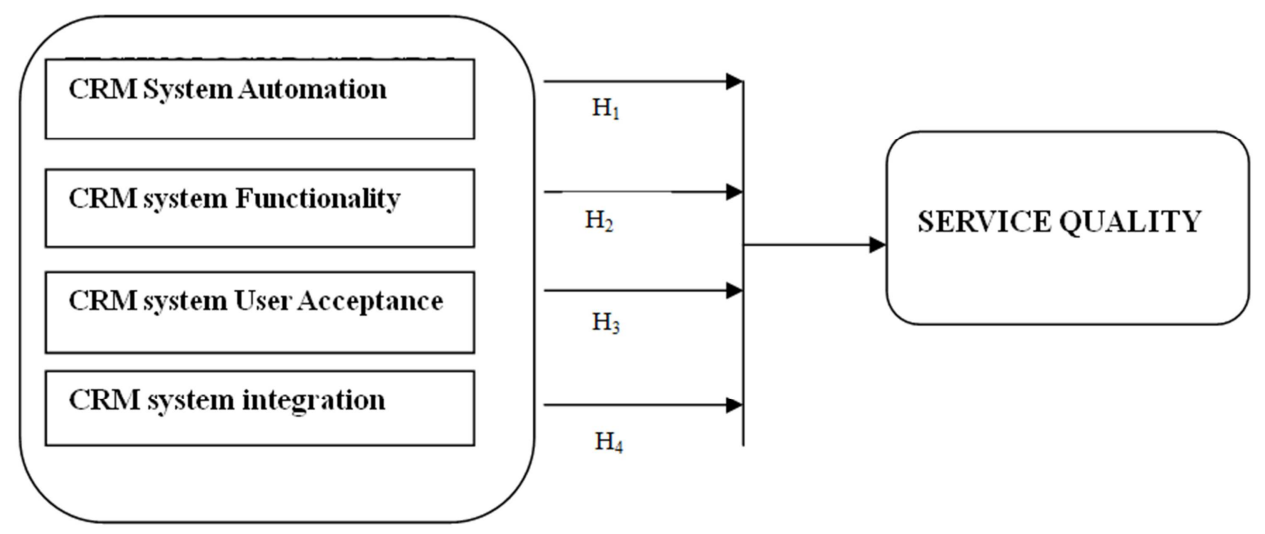

Figure 1. Conceptual Framework.

From the conceptual framework, four hypotheses were stated as follows:

Hypothesis 1: There is a relationship between CRM system automation and service quality in
Telecommunications industry in Arusha City.

Hypothesis 2: There is a relationship between CRM system functionality and service quality in Telecommunications industry in Arusha City. 
Hypothesis 3: There is a relationship between CRM system user acceptance and service quality in Telecommunications industry in Arusha City.

Hypothesis 4: There is a relationship between CRM system integration and service quality in Telecommunications industry in Arusha City.

\section{Methodology}

\subsection{Research Design and Population}

The study used descriptive research design to generate information for describing the effect of technology based CRM on service quality in telecommunications industry in Arusha City in Tanzania. This descriptive design used a cross sectional study where by data collection was done at a single point in time. The study targeted a population from the key players in the telecommunication industry in Tanzania including mobile phone operators, distributors and mobile phone subscribers. The total number of players (participants) in the industry was $26,514,895$. The attribute that made this population relevant was the ability to provide the information needed by the study.

\subsection{Sampling Design}

A multi stage sampling approach was used to select a representative sample for the study. In the first stage, stratified sampling method was used to group the respondents into three strata, namely the mobile phone companies, the distributors and customers. Stage two of the sampling involved determination of sample size. The study used mathematical formula adopted from Kothari [23]

Formula:

$$
\mathrm{N}_{\mathrm{C}}=\frac{\mathrm{z}^{2} \mathrm{p} \cdot \mathrm{qN}}{\mathrm{d}^{2}(\mathrm{~N}-1)+\mathrm{Z}^{2} \mathrm{p} \cdot \mathrm{q}}
$$

Where:

$\mathrm{N}_{\mathrm{C}}=$ is the desired sample size

$\mathrm{D}=$ desired level precision i.e 0.05

$\mathrm{N}=$ Total number of population in the targeted population

$\mathrm{Z}=$ is the confidence level (95\%) where $\mathrm{z}$ is equal to 1.96

$\mathrm{P}=$ is the proportion of the strata population for entire population

$\mathrm{Q}=$ or $(1-\mathrm{p})$ is the proportion to the total population

$\mathrm{d}=$ the desired level of statistical significance set (0.05)

Stage three of the process involved use of a disproportionate stratified method to distribute respondents to the various strata. This approach was deemed suitable since the population was not uniformly distributed to all the strata. The last stage involved application of purposive sampling method to select respondents through a purposive sampling for the first two strata and simple random sampling for the last stratum. Within the Mobile phone companies, the study targeted managers in the key departments of IT, Marketing, Operations and Customer Care. The distribution of the respondents across the various strata is shown in table 1.

The computed figure for the sample size using this formula was 323 .

Table 1. Sampling Frame.

\begin{tabular}{|c|c|c|c|c|c|}
\hline Strata & Frequency & Total respondents & Proportionate Ratio & Adjusted/disproportionate Ratio & Sample size \\
\hline Mobile companies & 4 & 40 & 0.0000015085 & 0.1 & 32 \\
\hline Distributors & 276 & 276 & 0.0000104092 & 0.2 & 65 \\
\hline Customers & $26,514,579$ & $26,514,579$ & 0.9999880821 & 0.7 & 226 \\
\hline Total & & $26,514,895$ & 1 & 1 & 323 \\
\hline
\end{tabular}

Source: Researcher, (2014)

\subsection{Data Collection and Analysis}

The study used a 5-point likert type questionnaire to obtain primary data. The questionnaire was first pretested for both validity and reliability before fieldwork commenced using a group of postgraduate students working at managerial levels who are enrolled in three universities in Kenya and Tanzania. Pretesting was considered important based on earlier observations to pilot test the questionnaire in ensuring validity and that the minimum number of questionnaires to be pilot tested should not be less than 10 questionnaires [12, 13]. The study pretested using a sample of 44 managers. The questionnaires were tested for construct and content forms of validity in to ensure conformity with relevant guidelines for ensuring research instrument validity [26]. The study used Cronbach Alpha score to compute reliability score for the instrument prior to and after the main survey. The test was done to the two sets of questionnaires, one for the mobile phone subscribers and the second for the mobile phone service providers and their respective distributors. The acceptable Alpha value that meets the statistical requirement for the instrument to be characterized as reliable should be 0.70 and above [46]. The Alpha score for both questionnaire sets was within the given range.

The study used both descriptive and inferential statistics for data analysis. Descriptive statistics were used to summarize the characteristics of all variables in the administered questionnaires in order to present the data in a more meaningful way, which allowed simpler interpretation of the data. Inferential statistics aimed at testing the hypotheses. The research applied linear regression analysis to test the hypotheses depicted in the conceptual framework.

\section{Findings}

\subsection{Response Rate and Respondents' Characteristics}

The total number of questionnaires distributed was 323, where by 226 questionnaires were distributed to mobile phone subscribers and 97 questionnaires were distributed to 
mobile phone operators and their distributors. The total number of questionnaires responded to was 293, that is, 214 from respondents' mobile subscribers (customers) and 79 respondents from mobile phone operators and in total representing a $90 \%$ response rate which was considered satisfactory for data analysis on the basis of the criterion for determining response adequacy in a survey [33]. The respondents' age groups between 18-25 and 26-35 were the majority users of mobile phone services where as the age group between 26 and 35 were the majority of the employees working in the telecommunications industry. This implied that the majority of the employees are having working experience of at least two years.

\subsection{Descriptive Findings}

Table 2 shows the summary of aggregate mean scores and standard deviation for each variable.

The likert scale was used as: $1=$ Not at All; $2=$ To Some Extent; 3=To a Fair Extent; 4=To a Good Extent and 5=To a Very High Extent

The aggregate mean score of CRM system automation is 3.6930 and standard deviation is 0.9265 , the aggregate mean score of CRM system functionality is 3.6962 and a standard deviation of 0.9360 , aggregate mean score of CRM system user acceptance is 3.6941 and a standard deviation of 0.9908 and CRM system integration scored aggregate mean of 3.8038 and a standard deviation of 0.9619 . All the mean scores for all the independent variables rounded off to the nearest whole number measured at 4 which corresponded to the level of a good extent according to the scale of the questionnaire used in the survey. The service quality variable's aggregate mean score is 3.4837 while the standard deviation is 1.1599 which corresponds to the level of fair extent.

Table 2. Summary of Descriptive Findings on Variables.

\begin{tabular}{|c|c|c|c|c|}
\hline Variable & $\begin{array}{l}\text { No. of } \\
\text { Items }\end{array}$ & $\begin{array}{l}\text { Aggregate } \\
\text { mean }\end{array}$ & $\begin{array}{l}\text { Standard } \\
\text { deviation }\end{array}$ & Comment \\
\hline $\begin{array}{l}\text { CRM system } \\
\text { automation }\end{array}$ & 4 & 3.6930 & .9265 & $\begin{array}{l}\text { To a good } \\
\text { extent }\end{array}$ \\
\hline $\begin{array}{l}\text { CRM system } \\
\text { functionality }\end{array}$ & 5 & 3.6962 & .9360 & $\begin{array}{l}\text { To a good } \\
\text { extent }\end{array}$ \\
\hline $\begin{array}{l}\text { CRM system user } \\
\text { acceptance }\end{array}$ & 6 & 3.6941 & .9908 & $\begin{array}{l}\text { To a good } \\
\text { extent }\end{array}$ \\
\hline $\begin{array}{l}\text { CRM system } \\
\text { integration }\end{array}$ & 4 & 3.8038 & .9619 & $\begin{array}{l}\text { To a good } \\
\text { extent }\end{array}$ \\
\hline Service quality & 16 & 3.4837 & 1.1599 & $\begin{array}{l}\text { To a fair } \\
\text { extent }\end{array}$ \\
\hline
\end{tabular}

\subsection{Test of Hypotheses}

The regression output results are summarized in table 3 .

Table 3. Summary of Multiple Regression Analysis.

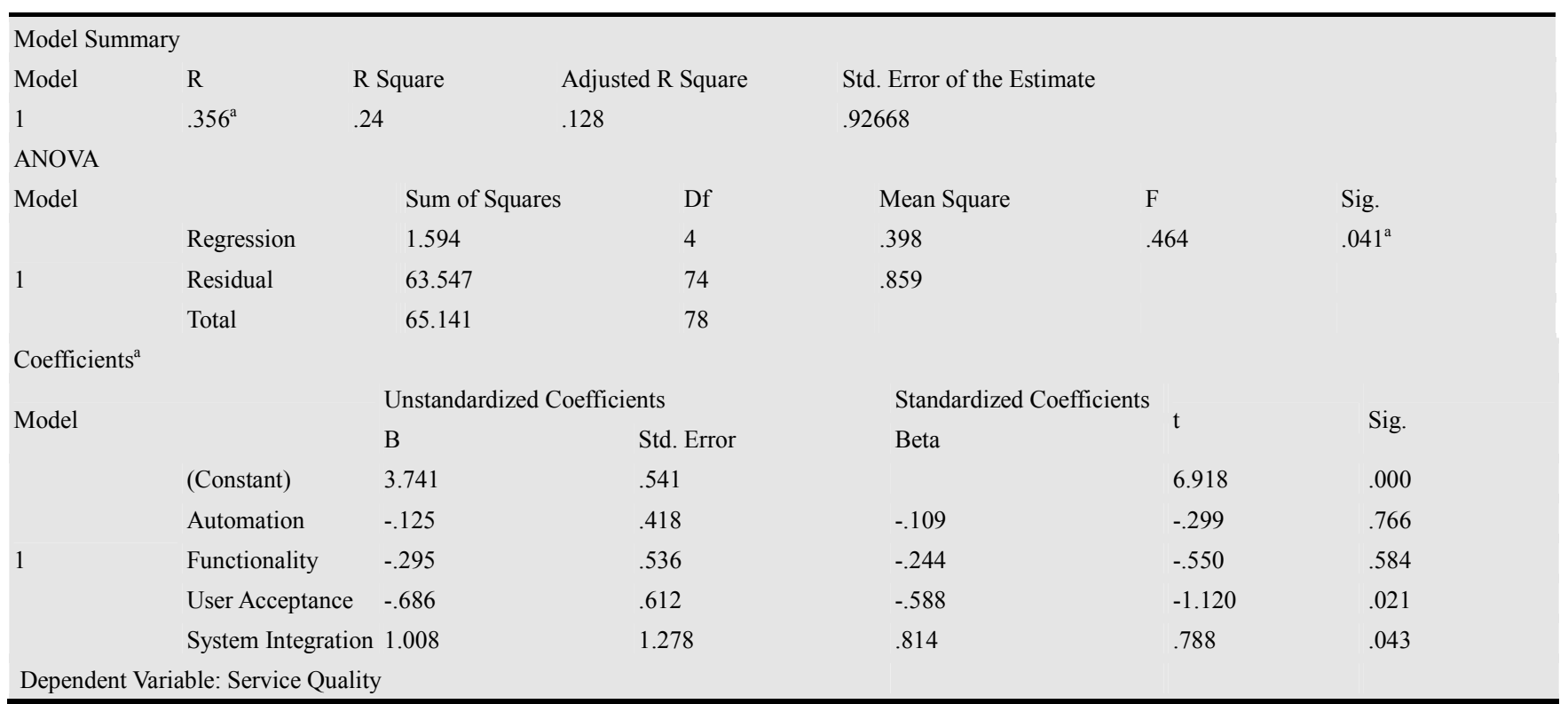

Hypothesis one sought to test the relationship between system automation and service quality, and the hypothesis was tested using multiple regression equation. The Beta coefficient of System Automation of -0.109 indicates that the direction of the relationship between System Automation and Service Quality is to a very small extent and negative. The statistical level of significance for this variable is $p=0.766$. The results from the analysis suggest that the null hypothesis is accepted. This leads to the conclusion that there is weak negative relationship between system automation and service quality that is not statistically significant. Hypothesis two tested the relationship between system functionality and service quality. The beta coefficient for the independent variable is -0.244 , which indicates that the relationship between system functionality and service quality is negative. The statistical level of significance for system functionality ( $P$ value) is 0.584 . Since the $p$ value is greater than 0.05 , the study accepts the null hypothesis and concludes that there is no statistically significant relationship between system functionality and Service Quality in the telecommunication industry in Arusha. Hypothesis three sought to test the relationship between system user acceptance and service 
quality. The beta coefficient for the independent variable is 0.588 , which indicates that the relationship between system user acceptance and service quality is negative. The statistical level of significance for system user acceptance ( $\mathrm{P}$ value) is 0.021 . Since the $p$ value is less than 0.05 , the study fails to accept the null and concludes that there is a statistically significant negative relationship between system user acceptance and Service Quality in the telecommunication industry in Arusha. The last hypothesis sought to test the relationship between system integration and service quality. The beta coefficient value is 0.814 implying that the relationship between system integration and service quality is positive. The $p$ value is 0.043 therefore; $p$ value is less than 0.05 . The results from the analysis meet the condition for failing to accept null hypothesis, which leads to the conclusion that there is statistically significant positive relationship between system integration and service quality.

\subsection{Discussion and Implications}

The results of hypothesis one and the conclusion made can be explained from both previous researches and the theories used to conceptualize the phenomenon investigated. The previous researches showed that installation of technology based CRM software alone is not enough to ensure that CRM program will be successful and profitable. The study indicated that a mere implementation of technology based CRM may not lead into desired results, and that at some other time it may even yield negative results [38]. The IT based model provides support for the adoption of IT based service options among service providers. It presents the argument based on the anticipated relationship between IT based services and customers perception of service quality. This aspect of the perception of the customers is important in determining whether the IT system in place is perceived to be enhancing the level of quality that the customers obtain. In the literature review, the study had raised the need for the integration of TQM models with the servqual model and identified the dimensions of quality connected with the aspects of perceived quality. This dimension is one that is psychological in nature in the mind of the customer. While the mobile phone companies have adopted Technology based CRM, such initiatives may have ignored the perceptions of the market. In marketing, consumer perceptions are considered important in driving customer purchase intentions and actual purchases. Furthermore, [31] the study presented the view that CRM is a concept that is highly supported by an integrated approach involving strategy, marketing and information technology. The results of hypothesis one may be indicative of the fact that the mobile phone companies have not achieved the required levels of integration among the areas of marketing strategy, marketing dimensions and the companies information technology and thus CRM fails to give optimal results that would offer a positive relationship between system automation and service quality.

The findings support the results of hypothesis two. Previous studies found that CRM process performance link was not strong and therefore suggested that the improvement of CRM implementation process is needed in ensuring a strong link between CRM process and performance [38]. Further, successful implementation of CRM largely depends on how well the internal marketing is managed and developed [9]. Boone and Kurtz, [6] also added that successful CRM relies on the firm's investment in training and interdepartmental communication. For technology based CRM to be successful, telecom companies may need to invest in internal marketing as well as integrating marketing systems with other aspects of business such as organization culture, structure and systems that support operations in the companies.

The findings of hypothesis three can be argued from a theoretical point of view, using the theories reviewed in this study. The Technology Acceptance Model argues that perceived usefulness and perceived ease of use of the existing information technology systems determine how users accept and use technology. However perceived usefulness and perceived ease of use determine the attitude toward using information technology systems, behavioral intentions to use IT system and actual use of IT system. On the other hand the Unified Theory of Acceptance and Use of Technology (UTAUT) argues that the four constructs that determine the behavioral intention and usage behavior of users of IT systems are moderated by age, gender, experience and voluntariness. The four constructs include performance expectancy (functionality), effort expectancy (user acceptance), social influence and facilitating conditions (system integration). This indicates that having the existing IT systems in the company alone is not enough to determine the behavioral intentions (future plans) and usage behavior (actions) but it has to be moderated by the age, gender, experience and voluntariness of users. As a result, the telecommunications companies in Arusha have installed technology based marketing functions systems to assist in raising the level of service quality but without taking into consideration other factors that can determine future plans and actions of marketing functions systems in contributing to the service quality improvement. The study noted that majority of the employees working in these telecom companies who responded to the questionnaire were aged between 26 years to 45 years. Even though the study did not assess the likely influence of the demographic factors of the respondents, the age factor may have potential influence in determining behavioral intentions and usage behavior of the IT users.

The outcome of hypothesis four is supported by the findings of previous studies in this stream [26] that suggested that the success of technology based CRM highly depends on the level integration of business systems and activities within a company. However, the study [27] pointed that technology based CRM success highly depends on the appropriate integration of business processes, people and business activities that are put in place harmoniously. Authors from a previous study [45] added that integration of CRM resources with other departments is important in ensuring customer service satisfaction. The integration is well facilitated by the 
presence of organizational culture that provides a conducive environment that supports integration of CRM activities with other business activities. However, [11] previous study had pointed that the marketing orientation that a company adopts is highly supported by the existing organizational culture. The Marketing philosophy is characterized by integration of functions within a company, customer focus of both internal and external marketing, profitability, competitiveness and careful planning. Along the customer focus perspective of this philosophy, it is argued that companies should not only pay attention to external markets but also to internal markets because the well managed internal markets are better off in organizing the internal activities of the organization and enhancing superior customer service that can positively impact the level of service quality. The findings of this hypothesis are also supported by the theoretical arguments of CRM Pyramid Model and the IDIC Model. These models indicate that a customer is a priority and a central focus to a firm, and therefore all the products and services offered to the customer should conform to needs. This is possible when the firms adopt an organizational culture that will allow the integration of appropriate marketing philosophy that consists of relevant marketing mix strategies. For the firms to be able to accommodate that, a strong base of suitable information technology based CRM is required in building a closer relationship with customers. However building relationship with customers entails a process with a number of steps and this process requires integration of business activities at each stage of the process. The first step is identifying customers to the business and building a deep understanding of them in terms of their behavior and needs. The second step is differentiation whereby a company has to differentiate their customers by identifying which customers have most value now and which offer most for the future. The third step is interaction, where by a company interacts with customers to ensure that customers' expectations are well understood, this step is crucial because it is where company gets a chance to relate and work together with customers through customer service touch points such as call centers and points of sale. In the case of mobile phone companies, this step is crucial too and has a positive impact on the level of service quality and signifies that customer service and service quality relate positively. The last step in building relationship with customers is customization which requires a company to customize its offers and communications to ensure that expectations of customers are met. Thus, through the findings of hypothesis four, it is observed that telecommunications companies in Tanzania have installed a technology based CRM system that supports the integration of business activities and processes to ensure service quality to its customers.

\section{Conclusion and Recommendation}

The study sought to understand the effect of technology based CRM on service quality. From the findings presented and the explanations offered, this study makes four conclusions. First, the study concludes that in the context of the telecommunication industry in Arusha Tanzania, CRM system automation affects service quality negatively and companies can attain higher levels of influence of system automation to service quality by integrating customers' perception of service quality with CRM system automation. Second, CRM system functionality has a significant negative influence on service quality, and that companies can enhance that relationship by integrating internal marketing as well as cultivating organizational cultures that will improve the level of service quality. Third, CRM system user acceptance has a negative effect on the level of service quality and that companies in telecommunications industry can improve this relationship by considering demographic characteristics particularly age and education of IT systems users that may have an influence in system user acceptance. Lastly, CRM system integration has a positive effect on the level of service quality and that companies in telecommunications industry can enhance the strength of this relationship by creating a close link and integration between technology based CRM systems, marketing philosophy and business functions.

The conclusions based on the findings face two limitations. First, even though the study obtained some demographic data from respondents, the study did not test the influence of these demographic factors to ascertain the possibility of an association with the variables in the study. Secondly, despite the fact that in the theory and previous empirical findings, internal marketing was used to offer explanations on the findings of this study, the study did not include measures of internal marketing so as to assess the exact role it would play.

In view of the limitations cited, the study makes three recommendations for future research. First, this study recommends further research to test the impact of the demographic factors of age, education and psychological state of individual users of technology based CRM to determine the level of service quality. The second area is on the use of non parametric statistics like Chi-square test of association to assess any possible association between technology based CRM and user demographic characteristics. The third area is on integrating internal marketing and corporate cultures with technology based CRM to determine the level of service quality

\section{References}

[1] Agyei, P. M. \&Kilika J. M. (2013). The Relationship between Service Quality and Customer Loyalty in the Kenyan Mobile Telecommunication Service Industry. European Journal of Business and Management, 5 (23).

[2] Baran, R. J., Galka, R. \& Strunk, P. D. (2008) Principles of Customer Relationship Management Thomson Ltd, USA.

[3] Berry, L. L. \& Parasuraman, A. (1991). Marketing Services. New York: The Free press.

[4] Bhatt, G. D. \& Emdad, A. F. (2010). The Role of Information Communication Technology in Customer Relationship Management. Journal of Systems and Information Technology. $12(1)$. 
[5] Blythe, J. (2006). Principles and Practice of Marketing. Thomson Learning.

[6] Boone, L. E. \& Kurtz, D. L. (2004). Contemporary Marketing, $11^{\text {th }}$ Edition. Thomson Learning.

[7] Bull, C. (2003). Strategic Issues in Customers Relationship Management Implementation. Business process Management Journal, 9 (5), 592-603.

[8] Buttle, F. (2009). Customer Relationship Management $2^{\text {nd }}$ Edition. Elsevier Limited.

[9] Chen, I. J \& Popovich, K. (2003). Understanding Customer Relationship Management (CRM): People, process and Technologies. Business Process Management Journal, 9 (5), 672-688

[10] Curry, A. \& Kkolou, E. (2004). Evaluating CRM to Contribute to TQM Improvement -a cross -case comparison. The TQM Magazine, 16 (5), 314-324.

[11] Egan, J. (2008). Relationship Marketing, Exploring Relational Strategies in Marketing, $3^{\text {rd }}$ Edition. Pearson Educational Limited.

[12] Fink, A. (2003). How to Ask Survey Questions. (2nd Ed). Thousand Oaks, CA: Sage.

[13] Fink, A. (2003). The Survey Handbook. (2nd Ed). Thousand Oaks, CA: Sage.

[14] Gabbott, M \& Hogg, G. (1997). Contemporary Service Marketing Management. Brace \& Company UK.

[15] Hutt, M. D. \& Speh, T. W. (2007). Business Marketing Management: $B 2 B, 9^{\mathrm{TH}}$ Edition. Cengage learning India private limited.

[16] Kapoor, R., Paul, J. \& Halder, B. (2011). Services Marketing. Tata McGraw Hill.

[17] Kotler, P. \& Armstrong, G. (1999). Principles of Marketing, $8^{\text {th }}$ Edition. Upper Saddle River, NJ: Prentice Hall.

[18] Kotler, P. (2000). Marketing Management. Prentice Hall, Upper Saddle River, New Jersey.

[19] Kotler, P. \& Keller, K. (2006). Marketing Management, Pearson Prentice Hall, Upper Saddle River, NJ, USA.

[20] Kotler, P. \& Keller, K. (2008). Marketing Management, 13Ed Pearson Prentice Hall, Upper Saddle River, NJ, USA.

[21] Kotler, P. \& Armstrong, G. (2006). Principles of Marketing. $11^{\text {th }}$ Edition. Pearson Education Limited.

[22] Kotler, P. \& Armstrong, G. (2012). Principles of Marketing. $14^{\text {th }}$ Edition. Pearson Education Limited.

[23] Kothari, C. R. (2004). Quantitative Techniques. New Delhi: Vikas Publishing House, PVT Ltd.

[24] Leisen, B. \& Vance, C. (2001). Cross- National assessment of service quality in Telecom industry: Evidence from USA and Germany. Journal of service quality 11(5), 307-317.

[25] Lucas, R. W. (2005). Customers Service, $3^{\text {rd }}$ Edition. McGraw Hill Companies, New York, America.

[26] MacKenzie, S. B. (2003). The Dangers of Poor Construct Conceptualization. Journal of the Academy of Marketing Science, 31(3), 323-326.
[27] Maklan, S. \& Knox, S. (2008). New Trends in Innovation and Customer Melationship Management: A Challenge for Market Mesearchers. International Journal of Market Research, Vol 50, No. 2, pp221-240.

[28] Materu, M. B., \& Diyamett, B. D. (2010). Tanzania ICT Sector Performance Review Towards Evidence-based ICT Policy and Regulation, 2 (11). Retrieved from: $\mathrm{http}$ //www.tanzania.go.tz/egov_uploads/documents/Vol $2 \mathrm{~Pa}$ per_11_Tanzania_ICT_Sector_Performance_Review_2010_s w.p.pdf.

[29] Mele, C. (2007). The Synergic Relationship between TQM Marketing in Creating Customer Value. Managing Service Quality, 17 (3), 240-258.

[30] McDaniel C. Jr., \& Gates, R. (1996), Contemporary Marketing Research, $3^{\text {rd }}$ Edition. West Publishing Company, U.S.A.

[31] McDonald, M. \& Christopher, M. (2003). Marketing, a Complete Guide. Palgrave Macmillan, New York.

[32] Mugenda, O. \& Mugenda, A. (2003). Research Methods: Qualitative and Quantitative Approach, Nairobi: ACTs press.

[33] Mkono, N. \& Kapinga K. W. (2014). Telecommunication Companies in Tanzania. Retrieved from hptt://www.mkono.com/pdf/ICLG_Tanzania.

[34] Nachmias, C. F. \& Nachmias, D. (2004). Research Methods in the Social Sciences, $5^{\text {Th }}$. Edition. London: Arnold.

[35] Parasuraman, A., Berry, L. L., \& Zeihaml, V. A. (1991). Refinement and Reassessment of the SERVQUAL Scale. Journal of Retailing, 67 (4), 420-450.

[36] Parasuraman, A., Berry, L. L., \& Zeihaml, V. A. (1988). SERVQUAL: A Multiple Item Scale for Measuring Consumer Perceptions of Service Quality. Journal of Retailing, 64(1), $12-40$.

[37] Petter, J. P. \& Donnelly, J. H. Jr. (2007). Marketing Management, $8^{\text {th }}$ Edition. McGraw Hill USA.

[38] Reinartz, W, Krafft, M. \& Hoyer, D. W. (2004). The Customer Relationship Management Process; Its Measurement and Impact on Performance. Journal of Marketing Research, 41 (3), $293-305$.

[39] Richard J. Semeki et. al. (1995). Principles of Marketing, Canadian Edition. Thomson Canada Limited.

[40] Richard J. E., Thirkell, P. C \& Huff, S. L. (2007). The Strategic Value of CRM: A Technology Adoption Perspective. Journal of strategic Marketing 15(5), 421-439.

[41] Salo, J. (2012). The Role of Mobile Technology in a BuyerSupplier Relationship: A Case Study from the Steel Industry. Journal of Business \& Industrial Marketing, 27(7).

[42] Seth, N. \& Deshmukh, S. G. (2004). Service Quality Models: a Review. International Journal of Quality \& Reliability Management, 22 (9), 913-949.

[43] Smith, A. D. (2010). Strategic Leveraging Total Quality and CRM Initiatives; Case Study of Service - Oriented Firms. Service Marketing Quarterly, 32(1), 1-16.

[44] Stallings, W. (2004). Data and Computer Communications (7th). Pearson Prentice Hall. ISBN 0-13-183311-1. 
[45] Thompson, K. R., Knox S. \& Maklan, S. (2009). Developing Relationship Marketing Through the Implementation of Customer Relationship Management Technology" Journal of Business and Marketing, 8(4), 58 - 66.

[46] Travakol, M. \& Dennick, R. (2011). Making Sense of Cronbach's alfa. International Journal of Medical Education 2(5), 3-55.

[47] Wang, Y., Po Lo, H. \& Yang Y. (2004). An Integration Framework for Service Quality, Customer Value Satisfaction: Evidence from China's Telecoms Industry. Journal of Information Systems Frontiers, 6(4), 325-340.
[48] Xu, Y., Yen, D. C., Lin, B. \& Chou, D C (2002). Adopting Customer Relationship Management Technology. Industrial Management \& Data System 102 (8), 442-452.

[49] Zineldin, M. (2005). Quality and Customer Relationship Management (CRM) as Competitive Strategy in the Swedish Banking Industry. The TQM Magazine, 17 (4), 329-344.

[50] Zineldin, M. (2006). The Loyalty of Loyalty: CRM, Quality and Retention. Journal of Consumer Marketing, 23, 430-437.

[51] Zhu, F. X., Wymer, W. \& Chen, I. (2002). IT Based Services and Service Quality in Consumer Banking. International Journal of Service Industry Management, 13 (1), 69-90. 